\title{
Diabetes Prevention Challenges In Arabic Region: A Call To Action Addressing The Cultural Context and eHealth
}

\author{
Hamzeh Awad* \\ Health and Medical Science department, Khawarizmi International University College, UAE
}

Submission: November 24, 2016; Published: December 02, 2016

*Corresponding author: Hamzeh J Awad, Associate Professor in Health Science and Health Information Technology, Al Khawarizmi International University College (KIC), UAE

\section{Introduction}

Diabetes mellitus (DM) affects more than 382 million people around the world, of whom $90 \%$ are diagnosed with type-2 DM (T2DM) [1]. The prevalence of T2DM has increased dramatically during the last 2 decades. The Arab world is not immune from this epidemic in the prevalence of T2DM. In fact, the Middle Eastern and North African region has the second highest rate of increase in diabetes globally, with the number of people with diabetes is projected to increase by $96.2 \%$ in 2035 [1,2].

The burden of DMT2, obesity, and cardiovascular disease is particularly high in Arabic countries. Obesity, physical inactivity, and excessive intake of nutrient-poor, calorie-rich foods are among the many factors contributing to this increased prevalence [3]. Indeed, the high risk of both diabetes and cardiovascular disease associated with obesity in Arabs may be due to a predisposition to abdominal obesity which can lead to the metabolic syndrome. According to the available data in the Arab world, overweight and obesity are prevalent even in poorer countries, as well as in low-income groups within these countries, exacerbating the burden on health authorities in the prevention and control of these diseases [4-9].

The silver lining is that, prevent or delay diabetes epidemic is possible. However, the impact and implementation of any prevention programme face a big challenge in ground. Therefore, this editorial sheds the light on central domain in any prevention program, namely cultural context, with consideration to Arabic community.

Prevalence of Diabetes in Developing Countries (Middle East and North Africa)

Globally, the prevalence of chronic, non-communicable diseases is increasing at an alarming rate. New figures by the International Diabetes Federation (IDF) indicate that the number of people living with diabetes is expected to rise worldwide from 366 million in 2011 to 552 million by 2030 . Also, $80 \%$ of people with diabetes live in low and middle income countries. In the
Middle East and North Africa Region, 32.6 million or $9.1 \%$ of the population now have diabetes and this number is expected to double in less than 20 years. IDF anticipates that by 2030, $11 \%$ of the Middle East and North Africa region or 59.7 million people will be living with diabetes; six out of the world's top ten countries [10]. WHO predicts that developing countries will bear the brunt of this epidemic in the 21st century [11].

In 1985 there were an estimated 30 million people with diabetes. Today diabetes affects more than 366 million people of the world's adult population [10]. With improvement in economic situation in developing countries, increasing prevalence of obesity and the metabolic syndrome is seen in adults and particularly in children. The main causes are increasing urbanization, nutrition transition, and reduced physical activity. Furthermore, aggressive community nutrition intervention programs for undernourished children may increase obesity. Some evidence suggests that widely prevalent perinatal under nutrition and childhood catch-up obesity may play a role in adult-onset metabolic syndrome and DMT2 [12].

Dagogo-Jack [13] reported that by the year 2025, more than three-quarters of all persons with diabetes will reside in developing countries [13]. One may recommend that an aggressive diabetes prevention programme (DPP) is urgently needed in order to stop this pandemic. Such programme should take into consideration an important domain in any public health prevention programme, namely the lifestyle changes. Indeed, addressing any lifestyle changes in Arabic countries require deep understanding for their culture and lifestyle.

\section{Culture and Diabetes}

According to the Social Science Encyclopedia, culture is defined as the way people live their lives [14]. It consists of conventional patterns of thought and behaviour, including values, beliefs and rules of conduct, which are passed from one generation to the next by learning and not by biological 


\section{Current Research in Diabetes \& Obesity Journal}

inheritance. For instance, what we eat or drink and what we believe depend largely upon our culture. As mentioned above that recent scientific evidence supports that the notion of diabetes prevention through lifestyle changes, addressing lifestyle changes in certain country or community need to take the cultural context into account from general and specific perspective.

\section{Developing countries between upholding their culture and shift to western lifestyles:}

The growing prevalence of type 2 diabetes and cardiovascular disease is tied to excess weight. In the past 20 years, the rates of obesity have tripled in developing countries that have been adopting a western lifestyle involving decreased physical activity and overconsumption of cheap, energy-dense food. Populationbased surveys of 75 communities in 32 countries show that diabetes is rare in communities in developing countries where a traditional lifestyle has been preserved. By contrast, some Arab, migrant Asian Indian, Chinese, and U.S. Hispanic communities that have undergone westernization and urbanization are at higher risk; in these populations, the prevalence of diabetes ranges from 14 to $20 \%$. In addition, most of the population growth in the developing world is taking place in urban areas [15].

As DMT2 is a disorder resulting from changes in lifestyle, one has to admit that there is a great need for health workers to be aware and sensitive to the cultural dimension and its significance in the care giving process [16]. The key issue after understanding the lifestyle of people is to help them change it toward healthy lifestyle. However, changing human behaviour is a complex clinical competency of the 21st century.

The literature on health behaviour change is usually specific to a given culture/community. Thus, this study will shed the light on one particular culture in developing countries, namely Arabic culture, and the pros and cons of cultural habits. Also, suggest some recommendations for the target population in order to prevent the widespread of diabetes.

\section{Who is an Arab?}

The term Arab is associated with a particular region of the world. Almost all of the people in the region extending from the Atlantic coast of Northern Africa to the Arabian Gulf. The classification is based largely on common language (Arabic) and a shared sense of geographic, historical, and cultural identity. The term Arab is not a racial classification, but includes peoples with widely varied physical features. Actually, there are 10 Arab countries in Africa (Morocco, Mauritania, Algeria, Tunisia, Libya, Sudan, Somalia, Eritrea, Djibouti and Egypt) and 12 countries in Asia (Iraq, Jordan, Lebanon, Syria, Kuwait, Bahrain, Qatar, Oman, United Arab Emirates, Saudi Arabia, Yemen, and the people of Palestine. Palestinians are presently either living under Israeli rule, autonomy of partial Palestinian Authority, or dispersed throughout the world. Despite the national boundaries drawn between the Arabs in the post-colonial period, the Arabs on the popular level view themselves as a unified entity. Arabs are not homogeneous with respect to religious belief, but include Christians, Jews, and Muslims. The large majority of Arabs are Muslim (92\%). The religion of Islam is closely associated with Arab identity because of the origin of Islam in the Arabian Peninsula and the fact that the language of Arabic is the sacred language of the Holy Koran.

\section{Diabetes and Arab-Islamic culture as a case in point}

The followers of Islam were founded in the seventh century by Prophet Mohammed in the Arabian Peninsula. The literal meaning of Islam means total submission to Allah. Muslims believe that the Islamic teachings should control every aspect of their life, whether great or small. Thus, understanding Muslims "correct" and "not correct" behaviour/lifestyle with related to social environment and diabetes prevention and intervention is the spine of a given editorial.

\section{Fatalism}

Although elements of free exist in Islam, Muslim society emphasis on fatalism as a result of repressive political and economic systems that have rendered people powerless. Fatalism the beliefs that events are controlled and predetermined by God "Allah" and that human have little, if any, control over their destinies is a psychological mechanism that reconciles people with their harsh reality and justifies their inability to control and shape their destinies. In diabetes, would be that they are unable to influence their disease in any way [17]. Indeed, Islamic society and its culture are based on the precise teachings of the Koran and the Sunna. Fatalism is a complex phenomenon; one may argue in this article that religious sentiments, including those that attribute a positive value to steadfastness in suffering, should not be seen as passive, as anti-science, or as constraints to medical treatment. In various ways, Muslims grappled with how to achieve the most benefit for themselves and their families while trying to conform to what would please God. Reliance on God, as an Islamic essence, should not be understood in opposition to seeking treatment or prevention, we should not ask whether patients appeal to God or seek treatment or strategic way for prevention, for one does not necessarily exclude the other. There is a social environment and social support to remain attentive to the interrelations between the two.

Fatalism in diabetes is not well documented; we still do not know much whether the perspective of fatalism is applicable among minority populations in different geographical location, and whether it is associated with different socioeconomic status. Given editorial highlights on two aspects of Muslims lifestyle and daily living activities and strongly related to diabetes and its development. The first one is related to an important domain of people lifestyle, namely diet. The second example is related to physical activity. These two domains are vital to any diabetes prevention or cure programme aim to be implemented in practice. 


\section{Current Research in Diabetes \& Obesity Journal}

Firstly, Hospitality and Generosity as Islam's Essence: exceed the limits and avoid diet. Arab Middle Eastern society can be characterized by intense and intricate rituals in which food fulfils important social functions. The host serves the guest food as a sign of hospitality and as a demonstration of honour to the guest. The guest accepts the food as a gesture of friendship, a sign of respect to the host, and as an affirmation of the host's prestige. Not only do hosts' offer foods unrestricted in variety, quantity and quality, but it is also customary to coerce the guests into eating above and beyond what they are capable of. In addition, The Arab hold negative views about slim or thin bodies in the case of both females and males, except in affluent sectors where the slender body type is preferred. For Arabs and many Africans, weight gain or plumpness is socially desired as a sign of beauty for women, and a sign of affluence and wealth for men [18]. Slim people are thought of as having tuberculosis, AIDS or cancer [19]. Thus, one does wonder where such believe among people comes from and whether Muslim Arabs, for instance, knowledgeable about healthy lifestyle. The Intrinsic complex phenomena seem to be hierarchy in which or what is accepted to be healthy (small portion size, limited rich and fatty food) rather than lack of knowledge. The social environment for Muslims supports the notion of modesty. For example, God say in Koran: "Eat and drink and be not immoderate" (Koran 7:31) [20]. Allah also says: "O you who believe, do not forbid the good things which Allah has made lawful for you and do not exceed limits. Surely Allah does not love those who exceed the limits" (Koran 5:90) [21]. One may suggest that such statements from Koran have a very positive meaning to toward well-being, thus, there is a need for a comprehensive approach address such Islamic statements and put it in action.

Secondly, physical activity as a central point for health and well-being: being Overweight as a measure of Prestige and Wealth status. In harsh contrast to Western culture, being overweight in the Middle East is historically associated with high social status. In actual fact, Overall fatness is associated with strength and wealth. People at risk of DMT2 or those have diabetes, therefore, may not be at all motivated to lose weight. In addition, weight loss is not desirable because it raises the suspicion that the person has a serious illness or has diabetes, as mentioned above. Even though the preference for body shape is gradually moving from fatness to thinness because of increased exposure to Western values through the media, this shift is taking place amongst the youth and is not necessarily affecting the population with type 2 diabetes which mainly consists of people over 40 due to IDF. Culturally, exercise and sports are viewed by some people as activities for young people [22]. Older people are excluded from exercise by the virtue of their senior status [23]. One may argue that there is an urgent need to shift toward the approach of exercise for young and old people in Arab-Muslim countries.

Islam social environment emphasis on not only a moderate and simple diet, as mentioned in the first example, but also on physical exercise/activity. For instance, the daily prayer is itself a form of exercise, as its prescribed movements involve all muscles and joints of the body, 5 times a day, as well as providing a way of meditation and relieving mental stress, this ultimately leads to Discipline. In fact, Living with diabetes or being at high risk of diabetes requires a lot of self-discipline in terms of careful attention to diet, rigorous timing of self-medication, frequent testing of blood sugar, sticking to an exercise regime and others.

\section{Opportunities for Improvement in Lifestyle from Arab-Muslim's and Public Health Perspectives}

a. Creating declaration on an Islamic perspective on diabetes similar to Amman/Jordan Declaration on an Islamic Perspective on Health supported and published by the World Health Organization, such declaration can be a resource for the health care practitioner and patient to guide healthy living practices in Arabic countries [24,25].

b. Health professionals need to assess an individual's motivation and willingness to stick to recommendations; the healthcare professional's may ask the person with diabetes to help develop his or her own plan of action to eliminate the secondary and tertiary complications. Perceived barriers towards the implementation of self-management can then be discussed, taking into consideration the daily lifestyle as well as the social environment.

c. DPP should translate "gold standard" programme to "real world" health care settings by identifying factors that may be barriers to the individual to implement each behavioural change as well as facilitators based on the environmental factors for individual persons, city, and country.

d. Centrifugal spread of local diabetes prevention information, agenda, guidelines from metropolitan to rural areas.

e. Raise the importance of family education and awareness in order shift habits and support in the prevention of diabetes (for example, the individual goal of healthy eating compared with the shame to the family of not providing guests with generous "special menu" food).

f. Religious teachings (Mosque, university and school) can be used to effect behaviour change based on verses from the Koran and Haddith, i.e. the examples of Koran used above, which supporting healthy lifestyle practices (e.g., guidance with respect to eating in moderation, being physically active, not smoking).

g. Run and organise public health workshop from Islamic perspective in order to increase the awareness of the Islamic perspective in diabetes at prevention and management level. Such workshops need to give practical examples for people form their own daily life and advise them to the right way. 


\section{Current Research in Diabetes \& Obesity Journal}

h. "Educated" Muslim women are seen as better able to resist social pressure and make up their own minds about taking exercise. [26] Suggests that critical health literacy may be a prerequisite for the goal of empowerment in ArabMuslim's society facing diabetes epidemic.

i. Health application, Smart phones represent $40 \%$ of total impressions in the Middle East, which is $45 \%$ higher than the global average, according to a report by In Mobi. Smartphone penetration in the Middle East region is projected to grow up to $39 \%$ by 2015 . [27-30] therefore, e Health applications can be useful for any lifestyle changes toward being physically active and use the mobile applications to perform active lifestyle.

To Sum up, the prevalence of diabetes has reached epidemic proportions. The $21^{\text {st }}$ century is hallmarked by lifestyle conditions which are associated with substantial social and economic burdens in developing countries, which contains several ethnic and religious groups. Arab-Muslims are, by far, one of the large population groups for Middle Eastern and African nations. Understanding their culture is crucial for any practical prevention or intervention programme, due to its relationship to bad and good behaviour, which with time may lead to diabetes and/or worsen its complications. We suggest understanding and differentiating which or what is accepted to be healthy in "Arab-Muslims society" and which or what is healthy in "reality". Also, screening studies considering lifestyle, level of physical actives, diet and environmental factors as well as culturally sensitive community-based strategies aimed at prevention and management of obesity and its metabolic complications would be crucial for any effective action. Furthermore, Islamic statements which enhance well-being and healthy lifestyle are urgently needed in order to shift the paradigm. Individual's misunderstanding for number of Islamic essences, i.e. Hospitality and Generosity, could be translated to cultural habits influencing people life and bring them many metabolic disorders such as diabetes. Therefore, an enormous effort among local countries is urgently needed in order to implement effective programmes and put it in action, mainly in areas where the level of education and health policy is at low level.

\section{References}

1. Wild S, Roglic G, Green A, Sicree R, King H (2004) Global prevalence of diabetes: Estimates for the year 2000 and projections for 2030 Diabetes Care 27(5): 1047-1053.

2. International Diabetes Federation. IDF Diabetes Atlas, $6^{\text {th }}$ edition. Brussels, Belgium: International Diabetes Federation 2013.

3. Boyle JP, Honeycutt AA, Narayan KM, Hoerger TJ, Geiss LS (2001) Projection of diabetes burden through 2050: Impact of changing demography and disease prevalence in the U.S. Diabetes Care 24(11): 1936-1940.

4. Al-Shayji IA, Akanji AO, (2004) Obesity indices and major component of metabolic syndrome in young adult Arab subjects. Ann Nutr Metab 48(1): 1-7.
5. Kelishadi R (2007) Childhood overweight, obesity and the metabolic syndrome in developing countries. Epidemiol Rev 29: 62-76.

6. Hossain P, Kawar B, Elnahas M (2007) Obesity and diabetes in the developing world a growing challenge. N Engl J Med 356(3): 213-215.

7. Harzallah F, Alberti H, Ben Khalifa F (2006) The metabolic syndrome in an Arab population: a first look at the new international Diabetes Federation Criteria. Diabetic Med 23(4): 441-444.

8. Ng SW, Zaghlool S, Ali HI, Harrison G, Popkin BM (2011) The prevalence and trends of overweight, obesity and nutrition-related non-communicable diseases in the Arab Gulf states. Obesity Rev 12(1): $1-13$.

9. Hossain P, Kawar B, Elnahas M (2007) Obesity and diabetes in the developing world a growing challenge. N Engl J Med 356(3): 213-215.

10. Diabetes Atlas, fifth edition. International Diabetes Federation, 2011.

11. WHO preventing chronic disease: A vital investment. (2005) World Health Organisation Geneva.

12. Misra A, Khurana L (2008) Obesity and the metabolic syndrome in developing countries. J Clin Endocrinol Metab 93(11 Suppl 1): S9-S30.

13. Dagogo-Jack S (2003) Ethnic disparities in type 2 diabetes: pathophysiology and implications for prevention and management. J Natl Med Assoc 95(9): 774; 779-789.

14. Kuber A, Kuber J, eds (1985) The Social Science Encylcopedia Routledge and Kegan Paul 178-180.

15. Hossain P, Kawar B, Elnahas M (2007) Obesity and diabetes in the developing world a growing challenge. N Engl J Med 356(3): 213-215.

16. Baker C (1991) Cultural awareness in diabetes. Can Nurse 87: 38-40.

17. Hjelm K, Isacsson A, Apelqvist J (1998) Healthcare profesionals perceptions of belief about health and illness in migrants with diabetes. Pract Diabetes Int 15(8): 233-237.

18. Ahmed AM, Hussein A, Kheir MM, Ahmed NH (2001) Impact of diabetes mellitus on Sudanese women. Pract Diabetes Int 18(4): 115-118.

19. Scott P (2001) Caribbean's people health beliefs about the body and their implications for diabetes management. Pract Diabetes Int 18(3): 94-98.

20. The Holy Koran, Sura number 7: 31.

21. The Holy Koran, Sura number 5:90

22. Koivisto VA, Felig P (1982) Exercise in diabetes. In: Diabetes mellitus. Rifkin H, Raskin P, eds. Robert Brady Co 137-144.

23. Tshbolala G, Gill GV (1999) Cultural aspects of diabetes in Africa Diabetes Int 9: 55-56.

24. Islamic ruling on smoking. 2nd ed. The Right Path to Health: Health Education Through Religion, World Health Organization, Regional Office for the Eastern Mediterranean, Alexandria.

25. (1997) Health: An Islamic perspective. The Right Path to Health: Health Education through Religion, 4. World Health Organization, Regional Office for the Eastern Mediterranean, Alexandria.

26. Nut beam D (2000) Health literacy as a public health goal: a challenge for contemporary health education and communication strategies into the 21st century. Health Promot Int 15(3): 259-267.

27. Estimates based on "Arab Knowledge Economy 2014", MADAR Research and Development 27. The ITU projects that the Arab region will reach 41 percent penetration in 2014: "The World in 2014: Facts and Figures", The International Telecommunication Union. 


\section{Current Research in Diabetes \& Obesity Journal}

28. Broadband Networks in the Middle East and North Africa: Accelerating High-Speed Internet Access. The World Bank.

29. The Arab Government Services Outlook (2014). 2nd Government Summit. Dubai: The Governance and Innovation Program, Mohammed Bin Rashid School of Government.
30.Global Information Technology Report 2014. World Economic Forum.

Your next submission with JuniperPublishers will reach you the below assets

- Quality Editorial service

- Swift Peer Review

- Reprints availability

- E-prints Service

- Manuscript Podcast for convenient understanding

- Global attainment for your research

- Manuscript accessibility in different formats

( Pdf, E-pub, Full Text, audio)

- Unceasing customer service

Track the below URL for one-step submission http://juniperpublishers.com/online-submission.php 